\title{
A Operação "Argus" (1958) e as controvérsias sobre a ocorrência de testes atômicos no Nordeste brasileiro*
}

\author{
Tácito Thadeu Leite Rolim**
}

O objetivo do artigo é discutir as conjecturas e especulações em torno de dois episódios ocorridos no Brasil no final da década de 1950. O primeiro deles foi uma explosão ocorrida nos céus de uma cidade do interior do Ceará, em julho de 1958, e o segundo a Operação "Argus”, conduzida pelo Departamento de Defesa estadunidense, entre agosto e setembro do mesmo ano. As apropriações feitas pelos sujeitos históricos de um e de outro episódio os levaram a associá-los a um possível teste atômico realizado clandestinamente no Nordeste brasileiro.

Palavras-chave: Guerra Fria - Operação "Argus” - Testes Atômicos

Operation "Argus" (1958) and the controversies about atomic tests in the Northeastern part of Brazil

The aim of this article is to discuss the speculations and conjectures involving two events that happened in Brazil in the end of the 1950's. The first one was an explosion in the skies of a city in the State of Ceará's hinterland in July of 1958. The second is the Operation Argus, conducted by the US Department of Defense, between August and September of 1958. These events were appropriated in such a way by

\footnotetext{
*Artigo recebido e aprovado para publicação em julho de 2009.

** Doutorando pelo Programa de Pós-Graduação em História da Universidade Federal Fluminense. E-mail: rolimtacito@yahoo.com.br
} 
their historical subjects that they were associated with a possible clandestine atomic test in the Northeastern part of Brazil.

Keywords: Cold War - Operation "Argus" - Atomic Tests

L'opération "Argus" (1958) et les controverses par rapport à la réalisation des tests atomiques dans le Nord-est du Brésil

L'objectif de cet article est d'investiguer les conjectures et les spéculations sur deux épisodes survenus au Brésil à la fin des années 1950. Le premier était une explosion survenue dans le ciel d'une petite ville de l'État du Ceará en juillet 1958. Le deuxième, l'opération "Argus"conduite par le Département de Défense des États-Unis entre les mois d'août et septembre de la même année. Les appropriations réalisées par les sujets historiques des deux épisodes ont mené à conclure à l'exécution d'un test atomique clandestin dans le Nord-Est du Brésil.

Mots-clés: Guerre Froide - Opération "Argus" - Tests nucléaires

Data: fins de julho de 1958. Local: Quixadá, uma pequena cidade no interior cearense. Aquela área do Sertão Central do estado era castigada por uma das "periódicas e catastróficas secas" que atingiam em cheio a população sertaneja: muito certamente este fenômeno climático emprestava um tom sombrio a toda paz e tranquilidade comuns às cidades interioranas. Naquela data, porém, muitos sertanejos e toda a população da área urbana da cidade foram testemunhas de um episódio inusitado: ao meio-dia a cidade "foi abalada com um estampido violento, que em nada pode se equivaler" e que foi "ouvido num raio de 60 quilômetros". O forte estrondo causou "verdadeiro pânico entre a população daquela cidade sertaneja". Segundo testemunhas, após a explosão, "se seguiu uma imensa coluna de espessa fumaça, dando a impressão de que se tratava de uma ocorrência verificada no próprio espaço". As mesmas testemunhas falam em "três explosões" e o periódico O Jornal

\footnotetext{
${ }^{1}$ Revista American Journal of Public Health, agosto de 1964, p.1.207-1.221, "A community health challenge - Northeast Brazil". O autor do artigo, Dr. George M. Leiby, é médico da Força Aérea norte-americana (USAF), e trabalhou como consultor da USAID no Nordeste brasileiro juntamente com o médico brasileiro, Dr. Fernando Figueira - coautor do artigo -, do Instituto de Medicina Tropical, em Recife, Pernambuco.

${ }^{2}$ Os periódicos de Fortaleza e as revistas Time pesquisados e utilizados neste artigo encontram-se disponíveis na Biblioteca Pública Governador Meneses Pimentel, em Fortaleza, Ceará. A revista Scientific American foi pesquisada na Biblioteca Setorial do Curso de Física da Universidade Federal do Ceará (UFC). O jornal nova-iorquino The New York Times foi pesquisado on-line no endereço eletrônico do jornal (www.nyt.com). Os exemplares da re-
} 
entrevistou o deputado estadual cearense Sebastião Brasilino de Freitas (UDN$\mathrm{CE})$, que estava em Quixadá no dia da "estupenda ocorrência". Segundo o deputado, "observou-se que uma fumaça esbranquiçada, tendendo para o cinzento, tomava corpo sobre os céus da região. A uma altitude aproximada ou ultrapassante dos 15 mil metros (...) a fumaça formou uma coluna de altura impossível de calcular-se, pela própria distância a que se encontrava”. E certo do que havia presenciado, o deputado afirmou: "Não há possibilidade de engano, pois o firmamento era de uma clareza ofuscante, e, como dizemos em linguagem aeronáutica, a visibilidade era infinita". ${ }^{3}$

O jornal fortalezense $O$ Povo especulou sobre a possibilidade de "deflagração de dinamite" ou de "explosão de teleguiado": ${ }^{4}$ a mesma opinião, no que se refere à explosão de um foguete teleguiado, foi compartilhada pelo deputado no O Jornal. Porém, afastou-se, logo de início, a possibilidade de "explosão de dinamite", uma vez que a explosão ocorrera sobre os céus da cidade: o jornal $O$ Estado, em matéria intitulada "Repercussão Nacional das Explosões em Quixadá", ${ }^{5}$ chegou mesmo a zombar da matéria do $O$ Povo, anunciando que um "Jornal de Fortaleza acredita estar havendo "explosões geológicas' no céu!...”

Percebe-se, a partir do noticiário dos periódicos, que as averiguações e as descrições do episódio indicam que não foi encontrada uma explicação satisfatória para ele. E, curiosamente, as explicações se tornaram mais sofisticadas na medida em que outros elementos analíticos foram incorporados ao conjunto delas. $\mathrm{O}$ meu objetivo, portanto, com este artigo, é mostrar como foi possível, a partir do episódio em Quixadá, discutir a possibilidade de que testes atômicos clandestinos teriam sido realizados em território brasileiro. Como foram unidos os fios que possibilitaram esta extraordinária hipótese? De que modo um episódio inusitado em uma pequena cidade do Sertão Central cearense possibilitou a aproximação do Brasil com toda a discussão mundial em torno dos perigos da radioatividade decorrente de explosões atômicas atmosféricas? Como reagiram os políticos e cientistas diante da gravidade da

vista Bulletin of the Atomic Scientists são de meu acervo pessoal. Quanto aos jornais do Rio de Janeiro, eles foram pesquisados e transcritos na Biblioteca Nacional, entre março e abril de 2008, quando da condução de pesquisas para o Doutorado na Universidade Federal Fluminense (UFF).

${ }^{3}$ Jornal O Jornal, Fortaleza, 29 de julho de 1958, p.1.

${ }^{4}$ Jornal O Povo, Fortaleza, 28 de julho de 1958, p.1.

${ }^{5}$ Jornal $O$ Estado, Fortaleza, 29 de julho de 1958, p.1. 
conjectura levantada? Há, atualmente, ecos gerados por toda a controvérsia em torno dos testes clandestinos?

Há cerca de um ano e meio antes da "estupenda ocorrência" em Quixadá, o governo brasileiro assinou um Acordo com os Estados Unidos para a instalação, na ilha de Fernando de Noronha, de uma base de rastreio de foguetes teleguiados, lançados a partir de Cabo Canaveral, Flórida. Em fins de 1956 o Conselho de Segurança Nacional discutira a permissão solicitada pelo governo norte-americano para a instalação das bases de rastreio em "pontos do território nacional, tais como Fernando de Noronha, Maceió, Natal, Fortaleza e Belém"6 e, a esta altura, o Conselho estava ciente de que "o Nordeste brasileiro (...) constitui centro nervoso de qualquer planejamento estratégico de defesa do Atlântico Sul"7. Estas reflexões - recorrentes também na bibliografia que lidava com a questão estratégica nacional ${ }^{8}$ - pareciam aproximar, mais e mais, o Nordeste do imaginário produzido pela Guerra Fria.

À época da assinatura do Acordo, em janeiro de 1957, os jornais de tendência comunista, como o fortalezense $O$ Democrata, já trombeteavam os riscos de se ter, em território brasileiro, uma estação de rastreio daquela natureza. Para uns, a "entrega" da ilha aos norte-americanos representou uma ameaça à soberania nacional, " enquanto, para outros, a "cessão" seria apenas um "ajuste" a acordos já previamente firmados - como o Acordo Militar Brasil-Estados Unidos, de 1952. Um intenso debate transcorreu entre "entreguistas" e comunistas sobre os termos do Acordo. Em um dado momento o jornal comunista antecipou: "É que, transformada a rota Flórida - Fernando de Noronha em percurso de experiência e de ação dos foguetes teleguiados, muitos destes serão atirados na direção do Nordeste brasileiro". ${ }^{10}$

${ }^{6}$ Ata da Vigésima-Primeira Sessão do Conselho de Segurança Nacional, 15 de dezembro de 1956, p.1.

${ }^{7}$ Ata da Reunião Parcial do Conselho de Segurança Nacional, 25 de setembro de 1956, p.5.

${ }^{8}$ Ver: Coronel Adalardo Fialho, Problemas do Brasil. Rio de Janeiro, Ministério da Guerra, Biblioteca do Exército, maio / junho 1952; General A. de Lyra Tavares, Segurança nacional: antagonismos e vulnerabilidades, Rio de Janeiro, Biblioteca do Exército, 1958; e General Antônio de Souza Júnior, O Brasil e a $3^{a}$ guerra mundial. São Paulo, Biblioteca do Exército, 1959.

9 “Aliás, Presidente JK, para entregar Fernando Noronha (...) nem seus conselheiros, nem V. Exa., se lembraram de que estavam rasgando a Constituição.” Assim, “o ano de 1957 caracterizou-se como um dos mais duros na ofensiva imperialista. Ocuparam a ilha de Fernando de Noronha e a costa do Nordeste, militarmente, violando nossa Constituição.” Osny Duarte Perreira, Estudos nacionalistas: considerações à margem do Brasil contemporâneo (Vol. 1), São Paulo, Fulgor, 1960, p.141 e 219.

${ }^{10}$ Jornal O Democrata, Fortaleza, 8 de janeiro de 1957, p.6. 
No calor do momento da ocorrência do episódio em Quixadá, a presença norte-americana na ilha servira de catalisador para que se adicionasse uma nova explicação às até então arroladas: a "tremenda explosão" era explicada, agora, como fruto da queda de um foguete teleguiado. Para muitos - notadamente os comunistas -, conviver com os norte-americanos há poucos quilômetros da costa brasileira significaria envolver-nos em um clima de guerra com a União Soviética, pois a "base de teleguiados de Fernando de Noronha tem finalidades agressivas, quais sejam as de lançar foguetes contra os outros países". ${ }^{11}$ O imaginário construído pela presença de uma estação rastreadora daquela natureza levou $O$ Democrata ${ }^{12}$ a supor que "lançados na direção do Atlântico Sul, (...) poderão [os foguetes teleguiados] explodir em qualquer parte do território brasileiro, especialmente na região Nordeste, semeando a morte e a destruição sobre cidades e vilarejos indefesos (...)". Adicione-se, a tudo isto, o fato de que em dezembro de 1956 um foguete norte-americano do tipo Snark - lançado do Cabo Canaveral - se precipitou, por conta de disfunções mecânicas, em alguma área da Amazônia brasileira. ${ }^{13}$ Este acontecimento ajudou a reforçar as associações e percepções que já vinham sendo construídas em torno de foguetes e mísseis teleguiados. ${ }^{14} \mathrm{Um}$ pouco mais adiante neste artigo mostrarei como estas reflexões pavimentaram o caminho rumo às futuras especulações sobre as atividades clandestinas do Departamento de Defesa estadunidense no Atlântico Sul.

Não pareceu difícil, portanto, para os jornalistas e demais testemunhas do episódio aludir sobre a possibilidade de que um foguete teleguiado tivesse se precipitado sobre a cidade. $\mathrm{O}$ jornal $O$ Povo, no entanto, atestando ter consultado a Base Aérea e a Secretaria de Polícia de Fortaleza, especulou sobre "pesquisas ou explorações geológicas naquela região" e aproxima-se mais da explicação da "deflagração de dinamite". Tal explicação foi, como mostrei, descartada posteriormente pela imprensa. Diz ainda $O$ Povo que a estação de rastreio na ilha "ainda não foi concluída", afastando-se o periódico da possibilidade ventilada de que foguetes teleguiados lançados de Fernando de Noronha fossem os responsáveis pela explosão. O deputado Sebastião Bra-

\footnotetext{
${ }^{11}$ Jornal O Democrata, Fortaleza, 8 de janeiro de 1957, p.6.

${ }^{12}$ Jornal O Democrata, Fortaleza, 14 de junho de 1957, p.2.

${ }^{13}$ Revista Air Force, Washington, dezembro de 2004, p.78-80.

${ }^{14}$ Tácito Thadeu Leite Rolim, "Giram os Sputniks nas alturas, ferve a imaginação nas planuras": a ciência e o bizarro no Ceará em fins da década de 1950, Fortaleza, 2006, 204 p., Dissertação (Mestrado em História Social) - Universidade Federal do Ceará.
} 
silino de Freitas, por outro lado, abraça a tese de que um engenho teleguiado "em experiência em qualquer parte do mundo" pode ter "provavelmente (...) escapado ao 'controle' da sua estação projetora" e se precipitado na área do município. Questionado quanto à existência de restos ou fragmentos do teleguiado, o deputado diz que nada foi encontrado. "Tudo é simples conjectura, mas o fato ocorreu, qualquer que seja a sua origem ou causa", conclui o deputado. O jornal carioca Última Hora, à época do ocorrido, confabulou com o deputado e este, de modo mais preciso, "procurou atribuir o fenômeno a explosão, naquele trecho do sertão cearense, de um dos foguetes lançados da base de Cabo Canaveral", ${ }^{15}$ por conta do lançamento de satélites artificiais norte-americanos. ${ }^{16}$

O curioso em tudo isto é que a estação de rastreio de mísseis e foguetes teleguiados instalada pelos Estados Unidos na ilha de Fernando de Noronha, ao que tudo indica, não se prestava ao lançamento de foguetes e/ou mísseis, teleguiados ou não. Como o próprio nome sugere, na ilha era apenas realizado o rastreio eletrônico dos engenhos em testes que eram lançados do Cabo Canaveral. Atualmente mantenho contato com um técnico telemetrista norte-americano, Sr. Wayne Zemany, que esteve em Fernando de Noronha no período de 1957-63. Segundo ele, não eram realizados lançamentos de mísseis e foguetes de Fernando de Noronha, apenas de balões-sonda para acompanhamento e monitoramento das condições meteorológicas. ${ }^{17}$ No entanto, no momento dos acertos iniciais para a construção da estação, o próprio Conselho de Segurança Nacional parecia acreditar na hipótese de que teleguiados seriam utilizados em Fernando de Noronha. Em Ata de dezembro de 1956, o Conselho parece reconhecer isto ao lembrar que estaríamos "sujeitos a represálias", em caso de guerra, "desde o momento em que proporcionamos aos nossos aliados facilidades para operações em território brasileiro de quaisquer engenhos ou instalações". ${ }^{18}$ [grifos meus]

${ }^{15}$ Jornal Última Hora, Rio de Janeiro, 3 de abril de 1959, p.3, "Pânico: Bombas Jogadas Nos Céus do Nordeste Ameaçam Milhões de Vidas!”

${ }^{16}$ Recordes no alcance dos mísseis eram rotineiramente quebrados e eles, assim, iam cada vez mais longe. Ver: Jornal The New York Times, Nova Iorque, 11 de julho de 1958, p.1, "Missile Fired 6,000 Miles, Setting a U.S. Testing Record".

17 "No rockets were launched from FDN, only weather balloons. We tracked the missiles from Cape Canaveral, Florida..." Correio eletrônico do Sr. Wayne Zemany, enviado no dia 3 de setembro de 2007, segunda-feira, 10h18min11s (Mon, 3 Sep 2007 10:18:11 -0700 (PDT)).

${ }^{18}$ Ata da Vigésima-Primeira Sessão do Conselho de Segurança Nacional, 15 de dezembro de 1956, p.4. 
O episódio foi, então, lentamente se apagando da memória das pessoas, fossem elas testemunhas oculares ou não do ocorrido. Um acontecimento que não causou maiores problemas para o município - não há registro de que alguém tenha morrido devido à explosão ou de danos materiais causados por ela - e que parecia não ter sido satisfatoriamente explicado: eis elementos que juntos pareciam condená-lo ao esquecimento. Porém outro episódio, igualmente inusitado, chamaria a atenção do mundo para o Atlântico Sul - e para o Nordeste brasileiro - no ano seguinte. A "estupenda ocorrência” ganharia vida nova e, mais impressionante ainda, uma nova explicação.

A segunda metade da década de 1950 foi um dos períodos mais frenéticos da chamada "Guerra Fria" no que se refere ao desenvolvimento e aperfeiçoamento de novas armas. A descoberta e o aprimoramento das armas nucleares - com a destruição de Hiroshima e Nagasaki servindo como laboratório de testes para atender a "curiosidade científica"19 de alguns cientistas do Projeto Manhattan - fez delas peças indispensáveis de uma próxima - e iminente - guerra nuclear. Nascia o que se convencionou chamar de a "Era Atômica": agora, a "corrida armamentista" e a "corrida espacial" ditariam os rumos da pesquisa científica, tanto civil como militar. Era preciso "melhorar" o desempenho das novas armas e isso significava torná-las mais mortíferas. Os vetores destas armas também tinham que ser aperfeiçoados e o Cabo Canaveral atinge o pico de lançamentos de testes de mísseis e foguetes neste período. No que se refere ao aprimoramento das armas atômicas per se, só os Estados Unidos conduziram, ao longo de mais de quarenta anos de pesquisa nuclear, mais de mil testes nucleares. ${ }^{20}$ Muitos destes testes espalharam silenciosamente partículas radioativas que eram carregadas pelos ventos para áreas próximas dos testes, assim como para regiões mais distantes, em todo o planeta. Foram especialmente os testes nucleares conduzidos no período conhecido como "Era de Testes Atmosféricos" (1951-1963) os maiores responsáveis pela disseminação de poeira radioativa e, consequentemente, pelo aumento no número de casos de câncer, leucemia, defeitos congênitos, dentre outros efeitos ainda não totalmente conhecidos.

\footnotetext{
${ }^{19}$ Peter D. Smith, Os homens do fim do mundo: o verdadeiro Dr. Fantástico e o sonho da arma total, São Paulo, Companhia das Letras, 2008, p.350.

${ }^{20}$ Para uma relação oficial dos testes nucleares realizados pelos norte-americanos, de 19451992, ver United States Nuclear Tests: July 1945 through September 1992, United States Department of Energy, Nevada Operations Office, Las Vegas, Nevada, December 2000. (DOE/NV-209REV 15).
} 
Mas que relação há entre armas atômicas, testes nucleares, radioatividade e a explosão em Quixadá? Inicialmente, um primeiro elo que nos une a tudo isto decorre do fato de o "único teste nuclear clandestinamente conduzido em 17 anos de história de testes atmosféricos [norte-americanos]"21 ter tido como sítio o Atlântico Sul - entre o sul da América do Sul e o sul da África do Sul. Este teste recebeu o codinome de Operação "Argus", e foi a primeira vez em que o Departamento de Defesa estadunidense escolhera um local para os testes nucleares fora do Oceano Pacífico (Atol de Bikini, Ilhas Marshall etc.) e do território americano (principalmente no estado de Nevada).

A Operação "Argus" foi conduzida secretamente pela Força-Tarefa 88, da marinha norte-americana, sob o comando do contra-almirante L. M. Mustin, entre fins de agosto e começo de setembro de 1958, e consistiu do lançamento de três foguetes de combustível sólido X-17 armados com ogivas nucleares de baixa intensidade (1,7 Kiloton $\left.{ }^{22}\right)$. Os foguetes foram disparados do navio USS Norton Sound e explodiram a uma altitude de aproximadamente $480 \mathrm{~km}$ : pela primeira vez na história dos testes, armas nucleares tinham sido disparadas de um navio em alto-mar e explodidas a uma altitude tão elevada. O objetivo dos testes foi o de criar cinturões de radiação artificiais ao redor da Terra, a exemplo dos cinturões de radiação natural recém-descobertos (os cinturões de Van Allen). Assim procedendo, estudariam as implicações militares de tais cinturões artificiais sobre as telecomunicações, radares, mísseis balísticos e suas ogivas nucleares. As razões para a manutenção do sigilo da Operação envolviam aspectos técnicos e diplomáticos: os norte-americanos não queriam que os russos monitorassem a Operação e assim tirassem dela algum proveito tecno-científico, assim como não queriam "provocá-los" com a execução de um teste nuclear a poucas semanas da moratória bilateral - entre EUA e URSS - de testes nucleares, que vinha sendo negociada para fins de outubro de 1958.

21 "Operation Argus was the only clandestine test series in the 17 years history of atmospheric testing". Ver http://nuclearweaponarchive.org/Usa/Tests/Argus.html, acessado em 20 de maio de 2008.

${ }^{22}$ Kiloton $(\mathrm{Kt})$ corresponde ao poder destrutivo de mil toneladas de explosivo TNT. Em média, as bombas atômicas lançadas em Hiroshima e Nagasaki tinham $20 \mathrm{Kt}$, ou seja, 20 mil toneladas de TNT. A União Soviética chegou a produzir - e testar - armas nucleares de 50 Mt (Megaton), por exemplo (ou 50 milhões de toneladas de TNT), conhecidas como "Monstros de Kruschev": parecia existir no inventário russo bombas de até $100 \mathrm{Mt}$ ! Ver: Peter D. Smith, op. cit., p. 442-444. 
Logo após a condução dos experimentos da Operação, a Força-Tarefa 88 aportou no Rio de Janeiro. Há, nos jornais e revistas cariocas da época, ampla divulgação da visita, com fotos das embarcações e entrevistas com os tripulantes. Uma destas revistas destaca em manchete que "O Rio foi prêmio de bom comportamento para 4 mil marujos" e apresenta uma série de fotos dos navios e, dentre elas, o do USS Norton Sound, fundeado na Baía de Guanabara: foi deste navio que partiram os três foguetes X-17. Segundo a revista os navios haviam feito um escala no Rio "depois de 3 meses de manobras de rotina no Atlântico Sul”. Perguntado, pelo repórter da revista, sobre a presença de armas atômicas nos barcos da Força-Tarefa, o contra-almirante Mustin disse que se reservaria ao direito de não responder a pergunta, afirmando que preferiria "deixar o repórter sem resposta". ${ }^{23}$

O segredo da Operação "Argus", porém, não durou muito tempo: em 1959 o jornal The New York Times - que fora informado do projeto meses antes da consecução da Operação - resolveu publicar matéria sobre ela, por julgar que a comunidade científica, jornalistas e os próprios russos já sabiam - ou desconfiavam - dela o suficiente para torná-la pública a qualquer momento. Assim, o jornal publicou ampla matéria em março daquele ano, dando detalhes e chamando-a de "o maior experimento científico" 24 já conduzido na História, dado os efeitos globais das explosões nucleares - criação de auroras boreais e austrais, e de um cinturão de radiação que envolveu a Terra por meses, dentre outros efeitos.

Um segundo elo que uniria armas atômicas, testes nucleares, radioatividade e a explosão de Quixadá foi estabelecido quando da repercussão da Operação "Argus" na imprensa da época, especialmente a carioca. As notícias de que armas nucleares tinham sido testadas tão perto de nós não foram bem recebidas por muitos políticos e cientistas, e suas inquietações encontraram eco nos jornais. Estes denunciavam que a radioatividade decorrente das explosões conduzidas no Atlântico Sul se precipitaria no Brasil e isto seria nocivo à saúde das pessoas. ${ }^{25} \mathrm{E}$ mais ainda: segundo o jornal carioca Última Hora, os testes nucleares clandestinamente conduzidos no Atlântico Sul, em meados de 1958, e a explosão ocorrida na cidade de Quixadá, em julho daquele mesmo ano, eram faces de uma mesma moeda. Para o jornal, portanto, os Estados

\footnotetext{
${ }^{23}$ Revista Mundo Ilustrado, Rio de Janeiro, 27 de setembro de 1958, p.16-19.

${ }^{24}$ Jornal The New York Times, Nova Iorque, 19 de março de 1959, p.1.

${ }^{25}$ Jornal Última Hora, Rio de Janeiro, 1 de abril de 1959, p.10, "Cientistas: 'Atuais Explosões Atômicas Podem Prejudicar as Gerações Futuras!’”
} 
Unidos conduziram experiências atômicas no Nordeste brasileiro. ${ }^{26} \mathrm{O}$ jornal insinuava, ainda, que a resposta que o contra-almirante Mustin não deu aos repórteres, à época da passagem da Força-Tarefa no Rio de Janeiro, encontrava sua explicação nos últimos acontecimentos. "A negativa era verdadeira. As bombas já tinham sido lançadas (...) indo explodir a cerca de $500 \mathrm{~km}$ de altitude e formando sobre os céus do Nordeste a nuvem que tanta inquietação está causando". ${ }^{27}$

Outro aspecto que parece lançar mais calor sobre a discussão acerca da Operação "Argus" está relacionado à confusão em torno da exata localização dos disparos. O jornal The New York Times repercute a notícia de que o episódio em Quixadá estava relacionado com a Operação: "Argus Tests Scored In Brazil", 28 denuncia o jornal. E mais, na mesma matéria, o jornal norte-americano diz que o "Nordeste brasileiro está a 1.000 milhas [cerca de $1.600 \mathrm{~km}$ ] da área de onde se relatou que os testes atômicos tinham sido conduzidos, em setembro". Segundo fontes oficiais do Departamento de Defesa norte-americano, os testes ocorreram entre o sul da América do Sul e o sul da África do Sul, num ponto próximo e ao sul do Arquipélago Tristão da Cunha: ocorre que este arquipélago está a pelo menos $3.600 \mathrm{~km}$ do ponto mais próximo da costa brasileira, o Rio de Janeiro. A revista científica Scientific American ${ }^{29}$ apresenta, como referência geográfica do ponto onde a Operação ocorreu, uma área localizada na "ponta da América do Sul". A revista semanal Time ${ }^{30}$ sugere que os disparos foram realizados ao largo das ilhas Falklands. Outra, como a The Bulletin of the Atomic Scientists, ${ }^{31}$ reporta que os testes clandestinos ocorreram no Pacífico Sul.

A exemplo da imprensa carioca, a imprensa cearense também noticia e especula sobre a fantástica possibilidade. Em tom dramático, o periódico Tribuna do Ceará anuncia: "Essa não Tio Sam: Três Bombas Atômicas Explodiram nos Céus do Nordeste Brasileiro"!32 O Jornal estampa em primeira página: "Experiência Atômica no Nordeste: a Operação Argus". ${ }^{33}$ A matéria atesta que os artefatos nucleares foram lançados a "cerca de 2.000 milhas a

${ }^{26}$ Jornal Última Hora, Rio de Janeiro, 4 de abril de 1959, p.5, "Após as Explosões Atômicas: Cientistas Exigem Medição da Radioatividade nos Céus do Nordeste".

${ }^{27}$ Jornal Última Hora, Rio de Janeiro, 6 de abril de 1959, p.1.

${ }^{28}$ Jornal The New York Times, Nova Iorque, 4 de abril de 1959, p.6.

${ }^{29}$ Revista Scientific American, Nova Iorque, maio de 1959, p.69-71.

${ }^{30}$ Revista Time, Nova Iorque, 30 de março de 1959, p.52.

${ }^{31}$ Revista Bulletin of the Atomic Scientists, Chicago, maio de 1959, p.223.

${ }^{32}$ Jornal Tribuna do Ceará, Fortaleza, 2 de abril de 1959, p.1.

${ }^{33}$ Jornal $O$ Jornal, Fortaleza, 1 de abril de 1959, p.1. 
leste e um pouco ao sul da Baia Blanca na Argentina" e que explodiram "bem ao largo do Nordeste Brasileiro". Uma semana depois, em matéria no mesmo jornal, fala-se que a explosão nuclear ocorrera na "Baia de Camarones, na Argentina" ${ }^{34}$ e o jornal sugere que a explosão do Nordeste brasileiro se trata de um episódio à parte, ao dizer que "Cientistas Brasileiros Falam Sobre as Terríveis Conseqüências das Explosões Provocadas pelos Norte-Americanos em Camarones [Argentina] e no Nordeste". Acentua-se, portanto, a confusão quanto à exata localização das explosões. Um desenho publicado na primeira página de $O$ Jornal, ${ }^{35}$ certamente repassado por uma agência internacional de notícias - as legendas estão sequer traduzidas -, sugere que os foguetes foram disparados do litoral da Argentina e explodidos ao longo da costa nordestina. Teria a distribuição deste desenho ajudado a disseminar mais confusão acerca da Operação "Argus"?

E não foi apenas na imprensa que encontramos referências ao teste nuclear clandestino no Nordeste brasileiro: o historiador Leôncio Basbaum, no livro Caminhos Brasileiros do Desenvolvimento - publicado em 1960 -, afirma em seu preâmbulo que "ainda recentemente os Estados Unidos fizeram explodir uma Bomba-A nos céus do Nordeste sem que os governantes e chefes políticos de nosso país se manifestassem de qualquer modo". ${ }^{36}$ Apesar de não citar a fonte de onde obtivera a informação, é certo que Basbaum estava se referindo à Operação "Argus". E mais ainda: em sua afirmação, Basbaum sugere complacência do governo brasileiro - no caso o do presidente Juscelino Kubitschek - para com o teste clandestino.

Em Fortaleza e no Rio de Janeiro, alguns deputados se mobilizaram contra as experiências atômicas no Nordeste. O deputado estadual José Pontes Neto (PSP-CE) denunciou o fato e "solicitou em seguida que a Assembléia se dirija por telegrama ao presidente da República e ao Conselho de Segurança Nacional, bem como ao Congresso", pois acreditava que a continuidade de experimentos desta natureza pode acarretar "conseqüências mortíferas para toda a população nordestina". ${ }^{37}$ Enquanto isto, na Capital Federal, o deputado federal Josué de Castro (PTB-PE), após declarar que o "Brasil não pode

\footnotetext{
${ }^{34}$ Jornal O Jornal, Fortaleza, 8 de abril de 1959, p.1.

${ }^{35}$ Jornal O Jornal, Fortaleza, 1 de abril de 1959, p.1.

${ }^{36}$ Leôncio Basbaum, Caminhos brasileiros do desenvolvimento: análise e perspectivas da situação brasileira, São Paulo, Fulgor, 1960, p.21.

${ }^{37}$ Ata da Décima-Sétima Sessão Ordinária da Primeira Sessão da $15^{a}$ Legislatura da Assembléia Legislativa do Estado do Ceará, em 8 de abril de 1959.
} 
submeter-se tacitamente ao papel de cobaia das mais graves experiências que têm sido empreendidas pela ciência mal-utilizada", "encaminhou à Presidência um requerimento de informações indagando quais instituições realizam controle da radioatividade no Brasill. ${ }^{38}$ Em São Paulo, em sessão realizada na Assembléia Legislativa no dia 1 de abril de 1959, moção foi encaminhada à Mesa "protestando contra a explosão de bombas atômicas nos céus do Nordeste do Brasil, primeira experiência feita por militares norte-americanos no Hemisfério Sul". ${ }^{39}$

E o debate em torno da possibilidade da ocorrência de testes nucleares clandestinos no Nordeste brasileiro não fica confinado somente na esfera política. A exemplo dos políticos, cientistas consagrados se manifestam sobre o episódio. No Rio de Janeiro, eles emitiram suas opiniões sobre as experiências clandestinas. O professor Leite Lopes e o cientista César Lattes, dentre outros, se posicionaram frontalmente contra a Operação "Argus". Para o professor Leite Lopes, o que os norte-americanos fizeram é comparável a "disseminar arsênico nas adutoras de água e depois recolher as vítimas para ver o efeito do veneno", e fuzilou enfurecido: "Não quero falar muito nesse assunto para não ficar nervoso". ${ }^{40}$ Já César Lattes, em matéria de OJornal, propôs uma "reunião de cientistas para estudar os efeitos da Operação Argus" e acrescentou que "o Brasil deve protestar" e não permitir que os Estados Unidos "lancem seus dejetos radioativos onde considerarem mais conveniente". ${ }^{41}$ Outros cientistas, no entanto, diziam que "não há perigo [de contaminação radioativa] quando as provas são realizadas a grandes altitudes": foi o que disse, em matéria no mesmo jornal fortalezense, o Almirante Otacílio Cunha, presidente da Comissão Nacional de Energia Nuclear. ${ }^{42}$ Repetia-se, portanto, em versão tupiniquim, o que já vinha ocorrendo nos Estados Unidos, no mesmo período, com relação ao perigo de contaminação radioativa das experiências nucleares ${ }^{43}$ no estado de Nevada: o governo nega peremptoriamente a possibilidade de contamina-

\footnotetext{
${ }^{38}$ Jornal Última Hora, Rio de Janeiro, 9 de abril de 1959, p.5, "Cientistas Alarmados: Poeira Atômica Ameaça Destruir a Vida no Nordeste!"

${ }^{39}$ Jornal Última Hora, Rio de Janeiro, 3 de abril de 1959, p.3, "Pânico: Bombas Jogadas Nos Céus do Nordeste Ameaçam Milhões de Vidas!"

${ }^{40}$ Jornal O Jornal, Fortaleza, 8 de abril de 1959, p.1, "Massa Atômica Estaria Envenenando Homens...”.

${ }^{41}$ Jornal O Jornal, Fortaleza, 15 de abril de 1959, p.4.

${ }^{42}$ Jornal O Jornal, Fortaleza, 13 de abril de 1959, p.6.

${ }^{43}$ Este assunto é amplamente discutido por Howard Ball, Justice downwind: America's atomic testing program in the 1950's, Nova Iorque, Oxford University Press, 1986 e Philip L. Fradkin, Fallout: an American nuclear tragedy, Boulder, Johnson Books, 2004; dentre outros.
} 
ção - alçado no discurso de técnicos e cientistas laureados pela comunidade científica internacional -, enquanto a população afetada e os cientistas insurgentes - muitas vezes taxados de comunistas - pouco ou quase nada podem fazer para deter a continuidade dos testes.

Vale salientar que os jornais da época não especulam, mas afirmam que testes atômicos foram executados no Nordeste brasileiro. Assertivas desta natureza causaram certo furor na comunidade científica nacional, exigindo reunião dos mesmos e o anúncio de que a "Comissão Nacional de Energia Nuclear deverá pronunciar-se, dentro de oito dias, oficialmente sobre as experiências atômicas realizadas no espaço sul-americano a altura do Nordeste brasileiro". ${ }^{44}$ Segundo o Consultor Jurídico do Ministério da Justiça, à época o Sr. Anor Butier Maciel, o Brasil poderia reclamar, junto à AIEA (Agência Internacional de Energia Atômica), "contra as explosões nucleares que venham a afetar o nosso território". ${ }^{45}$ No entanto, nas fontes em que pesquisei até o momento, não encontrei nenhuma manifestação oficial do governo brasileiro junto aquela agência sobre o episódio.

O que teria ocorrido no Nordeste brasileiro em fins da década de 1950? Em outra pesquisa que realizei sugeri que os lançamentos de mísseis e foguetes, realizados pelos Estados Unidos a partir de Cabo Canaveral, foram uma das prováveis explicações para o pulular de episódios inusitados em fins da década de 1950, no interior cearense. ${ }^{46}$ Encontrei, ainda, no jornal The New York Times, matérias que apontam que experiências com foguetes tripulados com animais (ratos e macacos) eram efusivamente conduzidas naquele período - também a partir do Cabo -, sendo que em uma delas, especificamente naquele mês e ano, o foguete e o seu tripulante - um rato chamado Wickie $e^{47}$ - se perderam e nunca foram encontrados. ${ }^{48}$ Estes experimentos foram conduzidos com o objetivo de testar a possibilidade do envio, no futuro, de um astronauta para o espaço, uma vez que se suspeitava da possibilidade

${ }^{44}$ Jornal Última Hora, Rio de Janeiro, 7 de abril de 1959, p.1, "Bomba Atômica no Nordeste: Cientistas vão Dizer Tudo!"

${ }^{45}$ Jornal Última Hora, Rio de Janeiro, 11 de abril de 1959, p.5, “Ministério da Justiça: Brasil Pode Reclamar Contra as Explosões Nucleares!"

${ }^{46}$ Tácito Thadeu Leite Rolim, "Um clarão rasgou os céus da cidade: o Ceará como palco da Corrida Espacial em fins da década de 1950". In: Ceará: Ciência, Saúde e Tecnologia. Fortaleza, Expressão Gráfica, 2007, p.115-136.

${ }^{47}$ Jornal The New York Times, Nova Iorque, 24 de julho de 1958, p.10, "Mouse in Missile Met the Press Before Taking Off Into Space".

${ }^{48}$ Jornal The New York Times, Nova Iorque, 26 de julho de 1958, p.5, "Air Force Halts Hunt for Mouse". 
do mesmo morrer ao ultrapassar os cinturões de radioatividade ao redor da Terra. Experimentava-se, portanto, a blindagem adequada do futuro veículo de reentrada e sua capacidade de resistir ao atrito com a atmosfera terrestre. ${ }^{49}$ Há ainda uma outra teoria, apresentada pelo médico carioca Olavo Fontes, de que a Operação "Argus" não atendia a estes propósitos, mas sim de que as armas atômicas foram "deliberadamente atiradas em um satélite misterioso" que orbitava em nosso planeta entre os dias 7 de julho e 6 de setembro de 1958. E pergunta: "Haveria realmente um inimigo extraterrestre contra o qual estamos nos preparando para se defender?" 50

Em entrevistas conduzidas há poucos anos, verifiquei que comunidades inteiras do Sertão Central cearense falam de um "intenso clarão nos céus", como "uma bola de fogo que explodiu" e que "havia transformado a noite em dia", ${ }^{51}$ exatamente nos idos de 1957 ou 1958. Em uma pequena cidade situada a pouco mais de cinquenta quilômetros a oeste de Quixadá, Madalena, o pároco local afirma hoje, categoricamente, que os supostos elevados casos de câncer do município são resultados de um "teste nuclear atmosférico em cima de nós". ${ }^{52}$ Ano após ano organizam-se eventos, palestras e seminários na cidade de Madalena - como o Seminário sobre Nuclearismo, realizado em julho de 2007 - de modo a manter acesa na memória dos seus habitantes um episódio que muitos lembram e poucos entendem, mas que nos últimos anos tem afetado o cotidiano e a memória dos habitantes da cidade. ${ }^{53}$

Na década de 1950, a atmosfera da "Guerra Fria" ajudou, em muito, na formulação das mais diversas conjecturas e especulações: tudo parecia possível

${ }^{49}$ Jornal The New York Times, Nova Iorque, 24 de julho de 1958, p.1, "3r. Missile Fired Across Atlantic in Re-Entry Test", "Ships and Planes Hunt Nose Cone Carrying a Mouse".

${ }^{50}$ Revista Flying Saucers, Wisconsin, outubro de 1959, p.8, "Project Argus, and the 'Anonymous' Satellite".

${ }^{51}$ Estas entrevistas foram conduzidas por mim, entre os anos de 2005 e 2006, na cidade de Madalena, no estado do Ceará. Gostaria aqui de agradecer ao pároco da cidade, senhor Richard Lee Cornwall, ou Padre Ricardo, que muito me ajudou na localização dos entrevistados e no fornecimento de apoio logístico. Agradeço também a Francisco Barbosa "Chiquinho" e Antônia Márcia, moradores da cidade. A Comissão de Direitos Humanos da OAB, Seção Ceará, chegou a produzir um vídeo - sob a direção de Francisco Alves e Valdeci Alves (Pathu Produções, 2001) -, sobre os supostos testes atômicos clandestinos em Madalena e que pode ser assistido no site do You Tube.

${ }^{52}$ Pronunciamento gravado em meio magnético (Fita K-7) do Padre Richard Lee "Ricardo" Cornwall, na Câmara de Vereadores da cidade de Madalena - CE. Data do pronunciamento: 06/08/2005. Hora: 9h30min. Local do pronunciamento: Câmara de Vereadores de Madalena - CE. Presidindo a Sessão: Vereador José Eurinaldo Vieira.

${ }^{53}$ Jornal O Povo, Fortaleza, 10 de março de 2003, p.5, "Mistério no Céu do Sertão Central". 
em fins da década de 1950 e "lá fora vivia-se o auge das ameaças da guerra fria (...)" ${ }^{54}$ Deste modo, até mais importante do que o episódio per se é pensar que foram levantadas hipóteses tão fantásticas quanto a da execução de testes atômicos em nosso território. Dito de outra forma: pensar que houve, em um dado momento de nossa história recente, uma fera política e ideológica que viabilizou a formação de um imaginário em torno desta possibilidade. Se há cinquenta anos a intenção dos "comunistas", ao ventilar aquela hipótese, foi a de acirrar as disputas em torno dos malefícios do "imperialismo ianque", é certo que, ainda hoje, de algum modo, ressoam ecos desta fantástica conjectura e especulação.

${ }^{54}$ Joaquim Ferreira dos Santos, Feliz 1958: o ano que não devia terminar, $5^{\text {a }}$ edição, Rio de Janeiro, Record, 1998, p.14. 